\title{
Unusual Twinning Resulting in Chimerism: A Systematic Review on Monochorionic Dizygotic Twins
}

\author{
Henrike E. Peters, ${ }^{1}$ Tamar E. König, ${ }^{1}$ Marieke O. Verhoeven, ${ }^{1}$ Roel Schats, ${ }^{1}$ Velja Mijatovic, ${ }^{1}$ \\ Johannes C. F. Ket, ${ }^{2}$ and Cornelis B. Lambalk ${ }^{1}$ \\ ${ }^{1}$ Department of Obstetrics and Gynecology, VU University Medical Center, Amsterdam, the Netherlands \\ ${ }^{2}$ Medical Library, VU University, Amsterdam, the Netherlands
}

\begin{abstract}
Traditionally, it is understood that dizygotic (DZ) twins always have a dichorionic placenta. However, with $8 \%$ blood chimerism in DZ twins, placental sharing is probably more common than previously has been recognized. In this article, we will review all available cases of monochorionic dizygotic (MCDZ) twins. A total of 31 twins have been described in literature. A monochorionic diamniotic placenta is reported in all cases. Assisted reproductive technology is responsible for the origin of the pregnancy in $82.1 \%$ of the cases. In $15.4 \%$ of the sex-discordant twins, a genital anomaly was reported in one of the twins. Chimerism is demonstrable in $90.3 \%$ of the twins, leading to various diagnostic difficulties. As this review shows that most MCDZ twins are discovered by accident, it can be argued that it is far more common than has been assumed until now. However, the prevalence is still unclear. Awareness of MCDZ twinning is important, with subsequently correct medical strategies. Similarly, the resulting (blood) chimerism is essential to consider in diagnostic procedures, pre- and postnatally. More research on the effect of placental transfusion between sex-discordant twins is required.
\end{abstract}

Keywords: dizygotic twins, monochorionic placenta, chimerism, prenatal testing, assisted reproductive technology

Traditionally, it is understood that monochorionic twins are monozygotic (MZ), and dizygotic (DZ) twins always have a dichorionic placenta. In recent years, researchers have become increasingly interested in atypical ways of twinning (McNamara et al., 2016). In 2000, the first welldocumented case of monochorionic dizygotic (MCDZ) twins was reported (Viëtor et al., 2000). Subsequently, several studies have reported this unusual way of twinning, and an association between assisted reproductive technology (ART) and MCDZ twinning has been suggested (Miura \& Niikawa, 2005). Well-known consequences of a monochorionic pregnancy include the higher obstetric risks, such as twin-to-twin transfusion syndrome (TTTS), intrauterine growth restriction, congenital malformations, and intrauterine fetal death. But this monochorionicity also means that vascular anastomoses, present in nearly all monochorionic pregnancies (Lewi et al., 2007), connect the two different fetal circulations. In MZ twins, the admixture of two blood cell lines with the same DNA remains unrecognized. But in $\mathrm{DZ}$ twins this results in intrauterine cell trafficking between the two different zygotes, resulting in blood chimerism. Blood chimerism means that in one organism two blood cell lines exist, from two genetically different zygotes. The first report of human blood chimerism dates back to 1953 (Dunsford et al., 1953). Even then, this was already a well-known phenomenon in cattle. The intrauterine blood exchange between male and female calves is recognized as the origin of the freemartin. This infertile female calve is lacking the Müllerian duct derivatives (Lillie, 1916). Vigier et al. (1984) stated that anti-Müllerian hormone (AMH) originating from the male co-twin arrives via vascular placental connections in the female calf-twin and is responsible for the freemartinism.

RECEIVED 27 October 2016; ACCEPTED 10 January 2017. First published online 27 February 2017.

ADDRESS FOR CORRESPONDENCE: Henrike E. Peters, Department of Reproductive Medicine, VU University Medical Center, Room no: PK 5x-194, de Boelelaan 1118, $1081 \mathrm{HZ}$, Amsterdam, the Netherlands. E-mail: h.peters@vumc.nl 
In human, however, little attention has been devoted to clinical consequences of twin chimerism. With $8 \%$ blood chimerism in DZ twins (van Dijk et al., 1996), this 'unusual' way of twinning is probably more common than previously has been recognized. Therefore, it seems important to assess clinical consequences, such as possible freemartinism in humans. By reviewing the available cases of MCDZ twins in literature, our aim is to create awareness of this relatively unknown twinning event. In addition, we attempt to formulate recommendations for clinicians dealing with MCDZ twin pregnancies and chimerism.

\section{Methods}

\section{Search Strategy}

This systematic review was performed in accordance with the Preferred Reporting Items for Systematic Reviews and Meta-Analysis (PRISMA) guidelines (Moher et al., 2009). The literature search was conducted (by H. P. and J. K.) using PubMed, Embase.com and ISI/Web of Science. These databases were searched from inception to 29 April 2016, with use of the following terms (including synonyms and closely related words): 'DZ twins and monochorionic', 'twins and chimerism', and 'freemartinism'. The full search strategies for all databases can be found in the supplementary material.

\section{Study Selection}

We considered all case reports and case series of MCDZ twins. We selected only articles in which a specific description of the placenta was available. Eligibility assessment of the retrieved articles was performed by one author (H. P.).

\section{Data Collection and Analysis}

From all included case reports, the following data were extracted: baseline data, method of conception, pregnancy data, birth outcomes, testing for chimerism, and physical examination of the twins. Relative frequencies were calculated and expressed in percentages.

\section{Results}

Through the literature search we identified 1,877 records. After removal of the duplicates, 1,219 records were screened based on title and, when unclear, on abstract. Figure S1 shows the flow diagram of the study selection following the PRISMA guidelines (see the supplementary material).

We included 31 unique cases of MCDZ twins, reported in 27 articles. The main characteristics of the cases are reported in Table 1. In all of the 31 cases, a monochorionic diamniotic placenta was documented by ultrasound during pregnancy or by macroscopic evaluation after birth. In $71 \%$ of cases, this was also confirmed by histological examination of the placenta.

\section{Conception}

In 28 cases, the method of conception was documented. These data are presented in Table 2. ART was responsible for the origin of the MCDZ twin pregnancy in $82.1 \%$ of the cases. More than half of the pregnancies were conceived after in vitro fertilization/intracytoplasmic sperm injection (IVF/ICSI) treatment. Three cases report assisted hatching during the ICSI procedure. In 17.9\% (five cases) the MCDZ twins arose from natural conception. Three of the naturally conceived MCDZ twins were sex-discordant and two pairs were male twins; the dizygosity in these male twins was in one case discovered after invasive prenatal testing and in the other case the parents arranged zygosity testing because of significant discordant features in the twins at the age of 14 months (Umstad et al., 2012).

\section{Obstetric Data}

In all cases, an ultrasound in early pregnancy reported absence of the lambda sign, confirming a monochorionic diamniotic placenta. However, when sex-discordance was noted on a following ultrasound, $7.4 \%$ of these pregnancies were nonetheless assumed to be dichorionic. In $16.1 \%$ of pregnancies, invasive prenatal testing was conducted (see Table 3). In two cases, the reason for invasive prenatal testing was the discrepancy between a monochorionic placenta and unexpected sex-discordance on ultrasound. TTTS was reported in $16.1 \%$ of the pregnancies, in two cases followed by laser therapy. Pregnancy loss under 24 weeks occurred in $6.5 \%$ of cases. Most (83.9\%) of the reported MCDZ twin pregnancies led to a live birth of twins.

\section{Clinical Presentation}

In $71 \%$ of the presented cases, two healthy twins were born without any described abnormalities. In $83.9 \%$ of the reported DZ twins a sex-discordance was noted. In $15.4 \%$ of the sex-discordant twins, a genital anomaly was reported in one of the twins (see Table 4), including one girl with aplasia of the Müllerian derivatives - possibly resembling the freemartinism in animals (Bogdanova et al., 2010).

\section{Chimerism}

In $90.3 \%$ of all cases, chimerism was demonstrable. Cytogenetic analysis of peripheral blood lymphocytes was performed by standardized G-banding technique and/or using FISH analysis. In four cases, chimerism was already revealed prenatally, but not always recognized. In 28 cases, the chimerism was discovered postnatally by cytogenetic analysis. In $32.1 \%$ of these cases, the chimerism was discovered by coincidence, and in $67.9 \%$, further investigations were initiated because of a sex-discordance and a monochorionic placenta.

In most cases, confined blood chimerism was reported: only present in hematopoietic tissue. The degree of blood chimerism altered from $1 \%$ to $99 \%$. In all cases in which the chimerism was tested after the postnatal period 
TABLE 1

Case Reports of Monochorionic Dizygotic Twin Pregnancies

\begin{tabular}{|c|c|c|c|c|c|c|c|}
\hline Year & Maternal & Conception & Obstetric information & $\begin{array}{l}\text { Delivery (GA in } \\
\text { weeks) }\end{array}$ & Chimerism & Phenotype & Follow-up \\
\hline Vietor et al. (2000) & 29 year G1P0 & - & - & 34 & Blood (+) Skin (-) & $\mathrm{M} / \mathrm{V}$ normal & 7 months \\
\hline Souter et al. (2003) & 48 year & IVF (donor oocytes) & $\begin{array}{l}\text { Spontaneous reduction } \\
\text { triplet }\end{array}$ & $37+0$ & Blood (+) Skin $(-)$ & $\mathrm{M} / \mathrm{V}$ normal & 5 months \\
\hline Johannsen et al. (2003) & - & IUI (donor sperm) & AFT: $X X / X Y$ & - & Blood (+) Skin (-) Ovaries (-) & $\mathrm{M} / \mathrm{V}$ normal & 15 months \\
\hline Quintero et al. (2003) & 28 year G1P0 & - & TTTS, laser & $\begin{array}{l}\text { Miscarriage } 2 n d \\
\text { trimester }\end{array}$ & - & $\mathrm{M} / \mathrm{V}$ normal & - \\
\hline Williams et al. (2004) & 38 year G3P1 & ICSI (AH+) & Pre-eclampsia & CS $28+0$ & Blood (+) Skin (-) Ovaries (-) & $\begin{array}{l}\text { V: clitoromegaly } \\
\text { M: normal }\end{array}$ & 7 weeks \\
\hline Ginsberg et al. (2005) & 35 year & clomid & $\begin{array}{l}\text { CVS: 2x 46XY AFT:1.XX } \\
\text { 2.XY }\end{array}$ & Immature - 22 & Amniotic fluid (+) & $\mathrm{M} / \mathrm{V}$ normal & Both twins expired \\
\hline Yoon et al. (2005) & 34 year G1P0 & ICSI & - & - & - & $\begin{array}{l}\text { M: } 47 X X Y+B W S \\
\text { M: normal }\end{array}$ & - \\
\hline Miura \& Niikawa (2005) & & & & & & & \\
\hline - Nishio et al. (2003) & - & IVF & - & - & Blood (+) Skin (-) & $\mathrm{M} / \mathrm{V}$ normal & - \\
\hline • Tsuruta (2003) & - & IUI & - & - & - & $\mathrm{M} / \mathrm{V}$ normal & - \\
\hline • Yamaguchi (2003) & - & ICSI & $\begin{array}{l}\text { Spont reduction triplet. } \\
\text { TTTS. }\end{array}$ & - & Blood (+) Skin (-) & $\mathrm{M} / \mathrm{V}$ normal & - \\
\hline • Niikawa (2004) & - & IVF & - & - & Blood (+) & $\mathrm{M} / \mathrm{V}$ normal & - \\
\hline • Niikawa (2004) & - & IVF & - & - & Blood (+) & $\mathrm{M} / \mathrm{V}$ normal & - \\
\hline Aoki et al. (2006) & 27 year G1P0 & clomid & - & $\mathrm{CS} 34+0$ & Blood (+) & $\mathrm{M} / \mathrm{M}$ normal & 3 months \\
\hline Shalev et al. (2006) & 39 year G4P2 & natural & $\begin{array}{l}\text { AFT: 1. } 46 X Y \text { 2. } 47 X Y+21 \\
\text { PUBS: } X Y / X Y+21\end{array}$ & $\begin{array}{l}\text { Termination 2nd } \\
\text { trimester }\end{array}$ & Blood (+) & $\begin{array}{l}\text { M: normal M: Down } \\
\text { syndrome }\end{array}$ & - \\
\hline Walker et al. (2007) & 30 year G2P1 & IVF & Hypertension, IUGR. & $\operatorname{CS} 36$ & Blood (+) & M/M: normal & 15 months \\
\hline Ekelund et al. (2008) & 38 year & ICSI (AH+) & $\begin{array}{l}\text { AFT: } 1.46 \mathrm{XX} 2.46 \mathrm{XY} \text {. } \\
\text { TTTS. }\end{array}$ & CS 32 & Blood (+) Buccal cells (-) & $\mathrm{M} / \mathrm{V}$ normal & 6 months \\
\hline Hackmon et al. (2009) & 33 year G3P2 & natural & - & SVD 37 & Blood (+) Buccal cells (-) & $\mathrm{M} / \mathrm{V}$ normal & 18 months \\
\hline Shaikh et al. (2009) & - & IVF & - & CS 34+1 & Blood (+) Buccal cells (-) & $\mathrm{M} / \mathrm{V}$ normal & - \\
\hline Bogdanova et al. (2010) & 32 year & IUI & Premature contractions & CS 32 & Blood (+) Buccal cells (-) & $\begin{array}{l}\text { M: normal V: Absence of } \\
\text { uterus + Down syndr }\end{array}$ & 2 years \\
\hline Assaf et al. (2010) & 28 year G1P0 & ICSI & AFT: M: 46XY. TTTS, laser & CS $37+4$ & Blood (+) Buccal cells (-) & $\mathrm{M} / \mathrm{N}$ normal & $\begin{array}{l}28 \text { months (Chen } \\
\text { et al., 2013) }\end{array}$ \\
\hline Hawcutt et al. (2011) & - & IVF & PPROM 24+2 & CS $25+1$ & Blood (+) Buccal (-) & M/V normal & 10 months \\
\hline Loriaux et al. (2011) & 30 year & - & TTTS. PPROM. IUFD boy & $29+5$ & Blood (+) Skin $(-)$ & M (IUFD)/V normal & 3 years \\
\hline Umstad et al. (2012) & 36 year & natural & $\begin{array}{l}\text { TTTS stage 1, no } \\
\text { intervention }\end{array}$ & $\operatorname{CS} 36$ & Blood (+) Buccal cells (-) & M/M normal & 14 months \\
\hline Choi et al. (2013) & 31 year G3P0 & ICSI (AH+) & IUFD girl AD 33+5 & CS & Blood (+) Skin (-) & $\begin{array}{l}\text { M: testicular hypoplasia } \\
\text { V (IUFD): normal }\end{array}$ & 39 months \\
\hline Kanda et al. (2013) & 28 year G1P0 & natural & Discordant growth & SVD $36+1$ & Blood (+) Skin (-) & $M / N$ normal & 1 year \\
\hline Smeets et al. (2013) & 37 year G4P1 & IUI & - & SVD 37 & Blood (+) Buccal cells (-) & $\mathrm{M} / \mathrm{V}$ normal & 3 weeks \\
\hline H.J. Lee et al. (2014) & 34 year G1P0 & IVF & - & SVD $38+0$ & Blood (+) Skin $(-)$ & $\mathrm{M} / \mathrm{V}$ normal & - \\
\hline Fumoto et al. (2014) & 32 year & ICSI & TTTS & CS 35 & Blood (+) Buccal, m (+)v (-) & $\mathrm{M} / \mathrm{V}$ normal & 11 months \\
\hline O.J. Lee et al. (2014) & - & IVF & - & - & Blood (+) Buccal (-) & $\mathrm{M} / \mathrm{V}$ normal & 23 months \\
\hline $\begin{array}{l}\text { Rodriguez-Buritica et al. } \\
\text { (2015) }\end{array}$ & 21 year G4P2 & natural & - & $\operatorname{CS} 39$ & Blood (+) Skin, m (+)v (-) & $\begin{array}{l}\text { M: hypospadias, aortic } \\
\text { stenosis. V: Normal. }\end{array}$ & 3 months \\
\hline $\begin{array}{l}\text { Mayeur Le Bras et al. } \\
(2016)\end{array}$ & 32 year G2P0 & clomid & $\begin{array}{l}\text { PPROM+ umbilical cord } \\
\text { prolapse }\end{array}$ & CS $36+1$ & Blood (+) Buccal (-) & $\mathrm{M} / \mathrm{V}$ normal & 5 months \\
\hline
\end{tabular}

Note: AFT = amniotic fluid test: $\mathrm{AH}$ = assisted hatching: CVS = chorionic villus sampling: CS = cesarean section: ICSI = intracytoplasmic sperm injection; IUFD = intrauterine fetal death; IUI = intrauterine insemination; IVF = in vitro fertilisation; PPROM = premature prelabour rupture of membranes; PUBS = percutaneous umbilical cord blood sampling; SVD = spontaneous vaginal delivery; TTTS = twin-to-twin-transfusion syndrome. 


\section{TABLE 2}

Conception of MCDZ Twins

\begin{tabular}{lll}
\hline Type of conception & & \\
\hline OI & $10.7 \%$ & ART total $82.1 \%$ \\
IUI & $14.3 \%$ & \\
IVF & $32.1 \%$ & \\
ICSI & $25 \%$ & \\
Natural & $17.9 \%$ & \\
Total & $100 \%$ & \\
\hline
\end{tabular}

Note: $A R T=$ assisted reproductive technology; $\mathrm{OI}=$ ovulation induction; IUI = intrauterine insemination; IVF = in vitro fertilization; ICSI = intracytoplasmic sperm injection.

(3 months-3 years), the chimerism was still detectable. In 21 cases, non-hematopoietic tissue was also tested for chimerism. Two cases reported tissue chimerism besides blood chimerism in one of the twins, namely buccal and skin chimerism.

Johannsen et al. (2003) report a case wherein nonrecognized chimerism led to a gonadectomy in a healthy girl. A male karyotype in this phenotypical girl was interpreted as $46, \mathrm{XY}$ gonadal dysgenesis. However, after removal, the ovaries were completely normal, with a normal female karyotype. The diagnosis was changed to blood chimerism.

\section{Discussion}

\section{Main Findings}

In this review, we present 31 cases of MCDZ twins, of which most were conceived after ART. Especially double embryo transfer in IVF/ICSI treatment seems to be a risk factor. Based on this review, it appears that there is a similar obstetric risk as for monozygotic monochorionic pregnancies; therefore, it is important to identify the MCDZ twin pregnancies. In $15.4 \%$ of the sex-discordant twins, a genital anomaly was reported in one of the twins. Confined blood chimerism was reported in most cases and was persistent into young childhood. The finding of chimerism can cause diagnostic difficulties, pre- and postnatally.

\section{Strengths and Limitations}

A potential limitation with case reports is that this method can involve publication bias. In particular, a publication bias regarding ART pregnancies and clinical consequences of chimerism must be considered. Nevertheless, due to the rarity, it was inevitable that case reports would be reviewed. This systematic review gives the first complete inventory of reported cases of MCDZ twins and shows what already is known about this unusual way of twinning. With 31 existing cases in literature since 2000, it is certain that MCDZ twinning is a topic that deserves attention. The strength of this review is the description of different outcomes of MCDZ twin pregnancies, with or without clinical consequences. This is important in medical decision making and counseling for the parents. Intrauterine cell trafficking between DZ twins and the long-term effects of chimerism are subjects that need further exploration. Follow-up studies of MCDZ twins would be of value.

\section{Interpretation}

Conception. A monochorionic diamniotic twin pregnancy suggests formation of the placenta between the 4th and 8th day after conception. Schiewe et al. (2015) have described the occurrence of MCDZ twin formation in vitro: 'Two prematurely hatching day- 5 blastocysts had merged together. These blastocysts had completely fused to form a single blastocoel cavity with two distinct inner cell masses' (pp. 418-419). This event supports the hypothesis posed by Souter et al. (2003) that trophoblasts from two embryos fuse before implantation, producing MCDZ twins. In 1970, the first case of chorionic fusion in a human placenta was reported, resulting in a partly monochorionic placentation in heterosexual twins. In one half of the placenta, a ridge with 'two layers of chorionic tissue between two layers of amnion' was found (like in dichorionic placentas), while the other half of the placenta was considered to be monochorionic after histologic examination (Nylander \& Osunkoya, 1970). Furthermore, when taking into account sporadic reports of fused dichorionic placentas (also resulting in chimerism), there may exist a sliding scale based on the time of fusion (Jang et al., 2010; Phelan et al., 1998). In the literature, other explanations have been discussed. It could be the presence of binovular follicles, in which two oocytes are present within a single zona pellucida. It is credible that this leads to close contact between embryos, whereby monochorionic placentation forms (Aoki et al., 2006). The most complex hypothesis contains an oocyte and second polar body surrounded by one zona pellucida, which is penetrated by more than one sperm (Dyban et al., 1992). While the precise explanation of MCDZ twin formation is uncertain, ART as a risk factor has been proposed before (Miura \& Niikawa, 2005). The various hypotheses also support the idea that with ART, the chance on MCDZ twins is increased. The chance of cell fusion seems smaller in a natural pregnancy, in which two blastocysts would not be likely to co-exist extremely close to each other. Possibly, assisted hatching could increase the chance of cell fusion. Moreover, binovular follicles appear more often in FSH-stimulated cycles (van de Leur \& Zeilmaker, 1990). These observations together support the idea that ART increases the risk of MCDZ twin formation.

Chimerism. The confined blood chimerism present in the majority of the MCDZ twins is a direct result of intrauterine blood sharing via the placenta. However, in two cases, tissue chimerism was also present. This is more difficult to interpret. Fumoto et al. (2014) discusses two different explanations: one consists of 'ectopic differentiation of chimeric hematopoietic stem cells' (p. e1099). Another possibility is that the chimera was generated at an early stage of embryogenesis, with double inner cell masses in one fused 


\section{TABLE 3}

Prenatal Testing in MCDZ Twin Pregnancies

\begin{tabular}{|c|c|c|c|c|}
\hline & AFT & CVS & Cordocentesis & Conclusion after PND \\
\hline Johannsen et al. (2003) & $\begin{array}{l}18 \text { wks: } \mathrm{XX} / \mathrm{XY} \\
\text { 'mosaicism' }\end{array}$ & - & - & $\begin{array}{l}\text { XX cell line judged as maternal cells. } \\
\text { Monozygotic males were suspected. }\end{array}$ \\
\hline Ginsberg et al. (2005) & $\begin{array}{l}20 \text { wks: } 1.46 X Y \\
\text { 2. } 46 X X\end{array}$ & $\begin{array}{l}11 \text { wks: } 2 \text { similar } \\
\text { results, } 46 X Y\end{array}$ & - & $\begin{array}{l}\text { AFT performed after conflicting result of } \\
\text { CVS and ultrasound (discordant sex). }\end{array}$ \\
\hline Shalev et al. (2006) & $\begin{array}{l}18 \text { wks: } 1.46 X Y \\
\text { 2. } 47 X Y+21\end{array}$ & - & $\begin{array}{l}20 \text { wks: } 1.35 \% 46 X Y / \\
65 \% 47 X Y+212.20 \% 46 X Y / \\
80 \% 47 X Y+21\end{array}$ & $\begin{array}{l}\text { Parents decided termination of the } \\
\text { pregnancy. }\end{array}$ \\
\hline
\end{tabular}

Note: AFT = amniotic fluid testing; CVS = chorionic villus sampling; PND = prenatal diagnosis; wks = gestational age in weeks.

\section{TABLE 4}

Genital Anomalies in Sex-Discordant MCDZ Twins

- Ambiguous external genitalia female (Williams et al. 2004)

- Absence of uterus/fallopian tubes (Bogdanova et al. 2010)

- Testicular hypoplasia (Choi et al. 2013)

- Glanular hypospadias (Rodriguez-Buritica et al. 2015)

blastocyst (as described before) where 'cells derived from one fetus could have migrated to the ectoderm of the other fetus' (p. e1100). It is possible this could result in chimerism in any organ, with still unknown consequences.

This review shows that the finding of chimerism is often unexpected and can cause diagnostic difficulties. Moreover, it can result in uncertainty for the caretaker and of course the parents, resulting in more diagnostic testing and confusion about the sex differentiation of the fetus/child. Therefore, it is important to consider the possibility of chimerism pre- and postnatally. Chorionic villus sampling and cordocentesis are prenatal diagnostic tests that reflect only the DNA in hematopoietic tissue. This means that blood chimerism can be the cause of a false test result, or the reason that a result is difficult to interpret. In amniotic fluid testing mostly fibroblasts will be analyzed, which makes it the most reliable test for chromosomal analysis in twins without detecting blood chimerism. Also postnatally, it is important to consider chimerism, illustrated by the case of Johannsen et al. (2003). Diagnosing blood chimerism involves at least comparing the karyotype in blood with other tissues (e.g., through buccal smear or skin biopsy). Furthermore, this review demonstrates that chimerism is still detectable in young childhood. This could point towards a permanent state. Several reports of coincidentally discovered chimerism in adult twins support this, with detectable chimerism until the age of 70 (Brüderlein et al., 2008; Kühl-Burmeister et al., 2000; Sharpe et al., 2014; Sudik et al., 2001). Chimerism (in specific feto-maternal microchimerism) is also a known subject in immunology, as it has been proposed that microchimerism may play a role in the etiopathogenesis of some autoimmune diseases (Mosca et al., 2003; Murata et al., 1999; Willer et al., 2006). A monochorionic placenta in DZ twins is, however, not the only possible cause for twin chimerism. Vascular anastomoses in a dichorionic placenta can also result in chimerism (Foschini et al., 2003). Even in singletons there are reports of (micro) chimerism, with a possible vanishing twin as the source for chimerism (de Bellefon et al., 2010). Consequently, the $8 \%$ prevalence of chimerism in DZ twins (according to van Dijk et al. (1996)) is probably only partially caused by monochorionic pregnancies. A challenging task for further research is to identify the different causes and long-term consequences of twin chimerism.

\section{Clinical Consequences}

Perinatal mortality and morbidity is considerably higher in monochorionic twin pregnancies than in dichorionic twin pregnancies (Hack et al., 2008). The higher obstetric risk seems similar for MCDZ twin pregnancies. This is illustrated by the prevalence of TTTS: $16.1 \%$ in MCDZ twin pregnancies versus $10-20 \%$ in 'normal' monochorionic pregnancies (Blickstein, 2006). Also, the risk of pregnancy loss under 24 weeks $(6.5 \%)$ is comparable with the reported risk in monochorionic pregnancies of $7.8 \%$ (Ghalili et al., 2013). However, a substantial part of the reported MCDZ twin pregnancies was incorrectly assumed to be dichorionic. It is important to identify MCDZ twins timely and correctly to take appropriate measures during pregnancy.

The prevalence of genital anomalies (15.4\%) in sexdiscordant twins can suggest an association with intrauterine cell trafficking. This would be comparable with the freemartin phenomenon in cattle (Lillie, 1916; Vigier et al., 1984). The case described by Bogdanova et al. (2010) could be the first published case of possible freemartinism in human. Also the case of testicular hypoplasia (Choi et al., 2013) is comparable with reports of testicular hypoplasia in bulls with confined blood chimerism (Bongso et al., 1981). This means that close observation of genital anomalies is recommended in chimeric twins. During pregnancy, counseling should be provided to parents expecting MCDZ twins with discordant sex. It is important to discuss the risk of a genital anomaly, but also to emphasize the possibility of healthy twins with normal development. 


\section{Conclusion}

Awareness of MCDZ twinning is important, with subsequently correct medical strategy in prenatal testing, pregnancy measures, and parental counseling. Similarly, the resulting (blood) chimerism is essential to consider in preand postnatal testing.

Most MCDZ twins are discovered by accident, and it can be argued that it is far more common than has been assumed until now. However, the prevalence is still unclear. Various hypotheses are posed for the origin of MCDZ twins; most point in the direction of fusion of two trophoblasts. An association of MCDZ twinning and ART is confirmed in this review; whether there is a causal effect remains uncertain. Additionally, it is possible that placental transfusion between sex-discordant twins can result in genital anomalies. More research is required for the effect of placental transfusion between DZ twins.

\section{Supplementary material}

To view supplementary material for this article, please visit http://doi.org/10.1017/thg.2017.4

\section{References}

Aoki, R., Honma, Y., Yada, Y., Momoi, M. Y., \& Iwamoto, S. (2006). Blood chimerism in monochorionic twins conceived by induced ovulation: Case report. Human Reproduction, 21, 735-737.

Assaf, S. A., Randolph, L. M., Benirschke, K., Wu, S., Samadi, R., \& Chmait, R. H. (2010). Discordant blood chimerism in dizygotic monochorionic laser-treated twin-twin transfusion syndrome. Obstetrics \& Gynecology, 116, 483485.

Blickstein, I. (2006). Monochorionicity in perspective. Ultrasound in Obstetrics \& Gynecology, 27, 235-238.

Bogdanova, N., Siebers, U., Kelsch, R., Markoff, A., Röpke, A., Exeler, R., ... Wieacker, P. (2010). Blood chimerism in a girl with Down syndrome and possible freemartin effect leading to aplasia of the Mullerian derivatives. Human Reproduction, 25, 1339-1343.

Bongso, T. A., Jainudeen, M. R., \& Lee, J. Y. (1981). Testicular hypoplasia in a bull with XX/XY chimerism. The Cornell Veterinarian, 71, 376-382.

Brüderlein, S., Müller, K., Melzner, J., Högel, J., Wiegand, P., \& Möller, P. (2008). Different rates of telomere attrition in peripheral lymphocytes in a pair of dizygotic twins with hematopoietic chimerism. Aging Cell, 7, 663-666.

Chen, K., Chmait, R. H., Vanderbilt, D., Wu, S., \& Randolph, L. (2013). Chimerism in monochorionic dizygotic twins: Case study and review. American Journal of Medical Genetics, Part A, 161, 1817-1824

Choi, D. H., Kwon, H., Lee, S. D., Moon, M. J., Yoo, E. G., Lee, K. H., ... Kim, G. (2013). Testicular hypoplasia in monochorionic dizygous twin with confined blood chimerism.
Journal of Assisted Reproduction and Genetics, 30, 14871491.

de Bellefon, L. M., Heiman, P., Kanaan, S. B., Azzouz, D. F., Rak, J. M., Martin, M., ... Lambert, N. C. (2010). Cells from a vanished twin as a source of microchimerism 40 years later. Chimerism, 2, 56-60.

Dunsford, I., Bowley, C. C., Hutchison, A. M., Thompson, J. S., Sanger, R., \& Race, R. R. (1953). A human blood-group chimera. British Medical Journal, 2, 81.

Dyban, A. P., De Sutter, P., Dozortsev, D., \& Verlinsky, Y. (1992). Visualization of second polar body chromosomes in fertilized and artificially activated mouse oocytes treated with okadaic acid. Journal of Assisted Reproduction and Genetics, 9, 572-579.

Ekelund, C. K., Skibsted, L., Søgaard, K., Main, K. M., Dziegiel, M. H., Schwartz, M., ... Tabor, A. (2008). Dizygotic monochorionic twin pregnancy conceived following intracytoplasmic sperm injection treatment and complicated by twin-twin transfusion syndrome and blood chimerism. $U l$ trasound in Obstetrics and Gynecology, 32, 832-834.

Foschini, M. P., Gabrielli, L., Dorji, T., Kos, M., Lazzarotto, T., Lanari, M., \& Landini, M. P. (2003). Vascular anastomoses in dichorionic diamniotic-fused placentas. International Journal of Gynecological Pathology, 22, 359-361,

Fumoto, S., Hosoi, K., Ohnishi, H., Hoshina, H., Yan, K., Saji, H., \& Oka, A. (2014). Chimerism of buccal membrane cells in a monochorionic dizygotic twin. Pediatrics, 133, e1097e1100.

Ghalili, A., McLennan, A., Pedersen, L., Kesby, G., \& Hyett, J. (2013). Outcomes of monochorionic diamniotic twin pregnancies: A comparison of assisted and spontaneous conceptions. Australian and New Zealand Journal of Obstetrics and Gynaecology, 53, 437-442.

Ginsberg, N. A., Ginsberg, S., Rechitsky, S., \& Verlinsky, Y. (2005). Fusion as the etiology of chimerism in monochorionic dizygotic twins. Fetal Diagnosis and Therapy, 20, 2022.

Hack, K. E., Derks, J. B., Elias, S. G., Franx, A., Roos, E. J., Voerman, S. K., ... Visser, G. H. (2008). Increased perinatal mortality and morbidity in monochorionic versus dichorionic twin pregnancies: Clinical implications of a large Dutch cohort study. BJOG, 115, 58-67.

Hackmon, R., Jormark, S., Cheng, V., O’Reilly, G. C., \& Divon, M. Y. (2009). Monochorionic dizygotic twins in a spontaneous pregnancy: A rare case report. Journal of MaternalFetal and Neonatal Medicine, 22, 708-710.

Hawcutt, D., Hammond, B., Sibbring, J., Gokhale, D., Ellis, I., Bricker, L., \& Subhedar, N. (2011). Twin-twin confusion syndrome: Blood chimerism in opposite sex dizygotic twins. Journal of Obstetrics and Gynaecology, 31, 446-448.

Jang, J. H., Jung, H., Kim, J. H., Park, W. S., \& Kim, S. H. (2010). Blood chimerism in a dizygotic dichorionic pregnancy. Korean Journal of Laboratory Medicine, 30, 521-524.

Johannsen, T. H., Lundsteen, C., Visfeldt, J., Schwartz, M., Petersen, B. L., Byskov, A. G., \& Müller, J. (2003). Erroneous genetic sex determination of a newborn twin girl due to chimerism caused by foetal blood transfusion: A case report. Hormone Research, 60, 148-151. 
Kanda, T., Ogawa, M., \& Sato, K. (2013). Confined blood chimerism in monochorionic dizygotic twins conceived spontaneously. AJP Reports, 3, 33-36.

Kuhl-Burmeister, R., Simeoni, E., Weber-Matthiesen, K., Milde, A., Herwartz, C., Neppert, J., \& Suttorp, M. (2000). Equal distribution of congenital blood cell chimerism in dizygotic triplets after in-vitro fertilization. Human Reproduction, 15, 1200-1204.

Lee, H. J., Yoon, S. C., Ko, J. M., Seong, M. W., Park, S. S., Choi, J. S., \& Oh, S. K. (2014). Monochorionic dizygotic twins with discordant sex and confined blood chimerism. European Journal of Pediatrics, 173, 1249-1252.

Lee, O. J., Cho, D., Shin, M. G., Kim, S. O., Park, J. T., Kim, H. K., \& Ryang, D. W. (2014). The first known case of blood group chimerism in monochorionic dizygotic twins in Korea. Annals of Laboratory Medicine, 34, 259-262.

Lewi, L., Cannie, M., Blickstein, I., Jani, J., Huber, A., Hecher, K., ... Deprest, J. (2007). Placental sharing, birthweight discordance, and vascular anastomoses in monochorionic diamniotic twin placentas. American Journal of Obstetrics and Gynecology, 197, 587.

Lillie, F. R. (1916). The theory of the freemartin. Science, 43, 611-613.

Loriaux, A., Boulet, S., Delorme, V., Althuser, M., Giroud, L. C., Grego, S., ... Jouk, P. S. (2011). Tetragametic chimerism: Case report. Journal de Gynecologie Obstetrique et Biologie de la Reproduction, 40, 77-80.

Mayeur Le Bras, A., Petit, F., Benachi, A., Bedel, B., Oucherif, S., Martinovic, J., ... Brisset, S. (2016). Confined blood chimerism in a monochorionic dizygotic sex discordant twin pregnancy conceived after induced ovulation. Birth Defects Research Part A: Clinical and Molecular Teratology, 106, 298-303.

McNamara, H. C., Kane, S. C., Craig, J. M., Short, R. V., \& Umstad, M. P. (2016). A review of the mechanisms and evidence for typical and atypical twinning. American Journal of Obstetrics and Gynecology, 214, 172-191.

Miura, K., \& Niikawa, N. (2005). Do monochorionic dizygotic twins increase after pregnancy by assisted reproductive technology? Journal of Human Genetics, 50, 1-6.

Moher, D., Liberati, A., Tetzlaff, J., \& Altman, D. G. (2009). Preferred reporting items for systematic reviews and metaanalyses: The PRISMA statement. British Medical Journal, $339,2535$.

Mosca, M., Curcio, M., Lapi, S., Valentini, G., D’Angelo, S., Rizzo, G., \& Bombardieri, S. (2003). Correlations of Y chromosome microchimerism with disease activity in patients with SLE: Analysis of preliminary data. Annals of the Rheumatic Diseases, 62, 651-654.

Murata, H., Nakauchi, H., \& Sumida, T. (1999). Microchimerism in Japanese women patients with systemic sclerosis. Lancet, 354, 220.

Niikawa, N. (2004). Clinical significance of monochorionic dizygotic twins. Paper presented at the Fourth Conference of the Pacific Rim Society for Fertility and Sterility, Isehara, Japan.

Nishio, K., Yokota, T., Sugiura, H., Oguri, I., Ueda, M., Hamashima, T., ... Naruse, H. (2003). Monochorionic di- amniotic twins discordant for gender (in Japanese; abstract from the 48th Annual Meeting of Japan Society for Premature and Newborn Medicine). Journal of Japan Society of Perinatal and Neonatal Medicine, 15, 534.

Nylander, P. P., \& Osunkoya, B. O. (1970). Unusual monochorionic placentation with heterosexual twins. Obstetrics \& Gynecology, 36, 621-625.

Phelan, M. C., Geer, J. S., \& Blackburn, W. R. (1998). Vascular anastomoses leading to amelia and cutis aplasia in a dizygotic twin pregnancy. Clinical Genetics, 53, 126-130.

Quintero, R. A., Mueller, O. T., Martinez, J. M., Arroyo, J., Gilbert-Barness, E., Hilbelink, D., ... Sutcliffe, M. (2003). Twin-twin transfusion syndrome in a dizygotic monochorionic-diamniotic twin pregnancy. Journal of Maternal-Fetal and Neonatal Medicine, 14, 279-281.

Rodriguez-Buritica, D., Rojnueangnit, K., Messiaen, L. M., Mikhail, F. M., \& Robin, N. H. (2015). Sex-discordant monochorionic twins with blood and tissue chimerism. American Journal of Medical Genetics, Part A, 167, 872-877.

Schiewe, M. C., Whitney, J. B., \& Anderson, R. E. (2015). Potential risk of monochorionic dizygotic twin blastocyst formation associated with early laser zona dissection of group cultured embryos. Fertility and Sterility, 103, 417-421.

Shaikh, S., Kaufman, R. M., Jardim, G. M., Hwang, D. G., Hirsch, M. S., Milford, E. L., ... Babic, A. M. (2009). Blood chimerism in monochorionic twins: An unusual cause of ABO discrepancy. Transfusion, 49, 114A.

Shalev, S. A., Shalev, E., Pras, E., Shneor, Y., Gazit, E., Yaron, Y., \& Loewenthal, R. (2006). Evidence for blood chimerism in dizygotic spontaneous twin pregnancy discordant for down syndrome. Prenatal Diagnosis, 26, 782-784.

Sharpe, C., Lane, D., Cote, J., Hosseini-Maaf, B., Goldman, M., Olsson, M. L., \& Hult, A. K. (2014). Mixed field reactions in $\mathrm{ABO}$ and $\mathrm{Rh}$ typing chimerism likely resulting from twin haematopoiesis. Blood Transfusion, 12, 608-610.

Smeets, D., Van Vugt, J. M. G., Gomes, I., Van Den Heuvel, S., Van Heijst, A., ... Claahsen-Van Der Grinten, H. L. (2013). Monochorionic dizygous twins presenting with blood chimerism and discordant sex. Twin Research and Human Genetics, 16, 799-801.

Souter, V. L., Kapur, R. P., Nyholt, D. R., Skogerboe, K., Myerson, D., Ton, C. C., ... Glass, I. A. (2003). A report of dizygous monochorionic twins. New England Journal of Medicine, 349, 154-158.

Sudik, R., Jakubiczka, S., Nawroth, F., Gilberg, E., \& Wieacker, P. F. (2001). Chimerism in a fertile woman with $46, \mathrm{XY}$ karyotype and female phenotype. Human Reproduction, 16, 56-58.

Tsuruta, S., Kida, Y., Hasegawa, H., Itai, M., Yoshida, K., Kitani, Y., \& Saito, Y. (2003). Monochorionic diamniotic twins discordant for external genitalia (in Japanese; abstract from the 48th Annual Meeting of Japan Society for Premature and Newborn Medicine). Journal of Japan Society of Perinatal and Neonatal Medicine, 15, 534.

Umstad, M. P., Short, R. V., Wilson, M., \& Craig, J. M. (2012). Chimaeric twins: Why monochorionicity does not guarantee monozygosity. Australian and New Zealand Journal of Obstetrics and Gynaecology, 52, 305-307. 
Van de Leur, S. J., \& Zeilmaker, G. H. (1990). Double fertilisation in vitro and the origin of human chimerism. Fertility and Sterility, 54, 539-540.

van Dijk, B. A., Boomsma, D. I., \& de Man, A. J. (1996). Blood group chimerism in human multiple births is not rare. American Journal of Medical Genetics, 61, 264-268.

Vietor, H. E., Hamel, B. C. J., Van Bree, S. P. M. J., Van der Meer, E. M. W., Smeets, D. F. C. M., Otten, B. J., ... Claas, F. H. J. (2000). Immunological tolerance in an HLA nonidentical chimeric twin. Human Immunology, 61, 190-192.

Vigier, B., Tran, D., \& Legeai, L. (1984). Origin of antiMullerian hormone in bovine freemartin fetuses. Journal of Reproduction and Fertility, 70, 473-479.

Walker, S. P., Meagher, S., \& White, S. M. (2007). Confined blood chimerism in monochorionic dizygous (MCDZ) twins. Prenatal Diagnosis, 27, 369-372.

Willer, C. J., Herrera, B. M., Morrison, K. M., Sadovnick, A. D., \& Ebers, G. C. (2006). Association between mi- crochimerism and multiple sclerosis in Canadian twins. Journal of Neuroimmunology, 179, 145-151.

Williams, C. A., Wallace, M. R., Drury, K. C., Kipersztok, S., Edwards, R. K., Williams, R. S., ... Zori, R. T. (2004). Blood lymphocyte chimerism associated with IVF and monochorionic dizygous twinning: Case report. Human Reproduction, 19, 2816-2821.

Yamaguchi, T., Seki, M., \& Sato, K. (2003). A case of dizygotic twins discordant for gender, showing TTTS and monochorionic placentation (in Japanese; abstract from the 48th Annual Meeting of Japan Society for Premature and Newborn Medicine). Journal of Japan Society of Perinatal and Neonatal Medicine, 15, 534.

Yoon, G., Beischel, L. S., Johnson, J. P., \& Jones, M. C. (2005). Dizygotic twin pregnancy conceived with assisted reproductive technology associated with chromosomal anomaly, imprinting disorder, and monochorionic placentation. Journal of Pediatrics, 146, 565-567. 